\title{
Comparison of Bayesian and partial least squares regression methods for mid-infrared prediction of cheese-making properties in Montbéliarde cows
}

\author{
M. El Jabri, ${ }^{1 *}$ M.-P. Sanchez, ${ }^{2}$ P. Trossat, ${ }^{3}$ C. Laithier, ${ }^{1}$ V. Wolf, ${ }^{4}$ P. Grosperrin, ${ }^{4}$ E. Beuvier, ${ }^{5}$ O. Rolet-Répécaud, ${ }^{5}$ \\ S. Gavoye,${ }^{3}$ Y. Gaüzère,${ }^{6}$ O. Belysheva, ${ }^{6}$ E. Notz, ${ }^{7}$ D. Boichard, ${ }^{2}$ and A. Delacroix-Buchet ${ }^{2}$ \\ ${ }^{1}$ Institut de l'Elevage, F-75012 Paris, France \\ ${ }^{2} \mathrm{GABI}$, INRA, AgroParisTech, Université Paris-Saclay, F-78350 Jouy-en-Josas, France \\ ${ }^{3}$ ACTALIA, F-39800 Poligny, France \\ ${ }^{4}$ Conseil Elevage 25-90, F-25640 Roulans, France \\ 5URTAL, INRA, F-39800 Poligny, France \\ ${ }^{6}$ Ecole Nationale d'Industrie Laitière et des Biotechnologies, F-39800 Poligny, France \\ ${ }^{7}$ Centre Technique des Fromages Comtois, F-39800 Poligny, France
}

\section{ABSTRACT}

Assessing the cheese-making properties (CMP) of milks with a rapid and cost-effective method is of particular interest for the Protected Designation of Origin cheese sector. The aims of this study were to evaluate the potential of mid-infrared (MIR) spectra to estimate coagulation and acidification properties, as well as curd yield (CY) traits of Montbéliarde cow milk. Samples from 250 cows were collected in 216 commercial herds in Franche-Comté with the objectives to maximize the genetic diversity as well as the variation in milk composition. All coagulation and CY traits showed high variability (10 to 43\%). Reference analyses performed for soft (SC) and pressed cooked (PCC) cheese technology were matched with MIR spectra. Prediction models were built on 446 informative wavelengths not tainted by the water absorbance, using different approaches such as partial least squares (PLS), uninformative variable elimination PLS, random forest PLS, Bayes A, Bayes B, Bayes C, and Bayes RR. We assessed equation performances for a set of $20 \mathrm{CMP}$ traits (coagulation: 5 for SC and 4 for PCC; acidification: 5 for SC and 3 for PCC; laboratory $\mathrm{CY}$ : 3) by comparing prediction accuracies based on cross-validation. Overall, variable selection before PLS did not significantly improve the performances of the PLS regression, the prediction differences between Bayesian methods were negligible, and PLS models always outperformed Bayesian models. This was likely a result of the prior use of informative wavelengths of the MIR spectra. The best accuracies

Received January 17, 2019.

Accepted April 23, 2019.

*Corresponding author: Mohammed.ElJabri@idele.fr were obtained for curd yields expressed in dry matter $\left(\mathrm{CY}_{\mathrm{DM}}\right)$ or fresh $\left(\mathrm{CY}_{\mathrm{FRESH}}\right)$ and for coagulation traits (curd firmness for PCC and SC) using the PLS regression. Prediction models of other CMP traits were moderately to poorly accurate. Whatever the prediction methodology, the best results were always obtained for CY traits, probably because these traits are closely related to milk composition. The $\mathrm{CY}_{\mathrm{DM}}$ predictions showed coefficient of determination $\left(\mathrm{R}^{2}\right)$ values up to 0.92 and 0.87 , and $\mathrm{RS}_{\mathrm{y}, \mathrm{x}}$ values of 3 and $4 \%$ for PLS and Bayes regressions, respectively. Finally, we divided the data set into calibration $(2 / 3)$ and validation $(1 / 3)$ sets and developed prediction models in external validation using PLS regression only. In conclusion, we confirmed, in the validation set, an excellent prediction for $\mathrm{CY}_{\mathrm{DM}}$ $\left[\mathrm{R}^{2}=0.91\right.$, ratio of performance to deviation (RPD) $=3.39]$ and a very good prediction for $\mathrm{CY}_{\text {FRESH }}\left(\mathrm{R}^{2}=\right.$ $0.84, \mathrm{RPD}=2.49$ ), adequate for analytical purposes. We also obtained good results for both PCC and SC curd firmness traits $\left(\mathrm{R}^{2} \geq 0.70, \mathrm{RPD} \geq 1.8\right)$, which enable quantitative prediction.

Key words: Montbéliarde, cheese-making property, mid-infrared spectroscopy, Bayesian method, partial least squares regression

\section{INTRODUCTION}

Controlling cheese-making properties (CMP) of milks, including raw milk, is important to provide financial return and ensure economic viability of the related dairy sectors. This is a sensitive issue in the current context of the end of the milk quota system, climate changes, and increase of production costs. A good milk for cheese-making is generally rich and balanced in mineral and clottable proteins, the caseins. During the cheese-making process, the milk should 
coagulate to obtain the typical curd composition and best curd yield (CY) for any cheese varieties. Curd composition and $\mathrm{CY}$ are the result of the joint action of rennet to form a casein network trapping fat, water, mineral, and other constituents of the milk and lactic fermentation to obtain, for any given technology, the correct values of $\mathrm{pH}$ and water content of the curd at demolding. Thus, CY, rennet coagulation, and acidification properties are 3 relevant criteria for testing and assessing milk CMP. All of these criteria are more or less linked to the fine chemical composition of the milk (Wedholm et al., 2006).

Nowadays, mid-infrared (MIR) spectroscopy is widely used to predict the gross milk composition (fat, protein, lactose). This method offers the prospect of rapid, real-time, and nondestructive evaluation of milk composition. Many studies have been carried out in the past $10 \mathrm{yr}$ to assess the possibility of using MIR spectroscopy to predict CMP of individual milks of various cow breeds to manage it routinely, time effectively, and at low cost (Dal Zotto et al., 2008; De Marchi et al., 2009, 2013; Visentin et al., 2015).

The reliability and accuracy of the predicted results depend to a great extent on the quality of the models and determine their practical applications (i.e., quality control, analytical, or breeding purposes; De Marchi et al., 2013; Ferrand-Calmels et al., 2014; Gottardo et al., 2015). They are related to the quality of the calibration data set and the spectra, and to the chemometrics techniques used to develop prediction models including variable selection, pre-treatment of spectra, and statistical model (Ferragina et al., 2017). Infrared spectral data are high dimensional. Most studies carried out on milk composition and CMP traits report predictions using partial least squares (PLS) regression models. More recently, collaborations between dairy food scientists and animal geneticists have led to the development of infrared prediction equations based on Bayesian models, commonly used for processing genomic data (Ferragina et al., 2015). Both PLS and Bayesian methods are able to handle data set where the number of variables far exceeds the number of samples. Unlike the first method, the accuracy of the second one is not affected by the presence of noise regions. The PLS is a linear technique and global calibration method. Variable reduction is performed by removing the spectral regions characterized by high noise and possibly by selecting the most informative wavelengths (Gottardo et al., 2015; Visentin et al., 2016). The latent variable number optimizes dimension reduction. Bayesian methods are powerful algorithms that estimate shrinkage of variables, with the choice of the prior density assigned to studied effects, and perform variable selection and dimension reduction (de los Campos et al., 2013a). The PLS and Bayes methods have led to infrared prediction equations, each with a different level of performance, depending on models, traits, and populations studied (Ferragina et al., 2015; Bonfatti et al., 2017).

The Franche-Comté region is the first producing region of Protected Designation of Origin (PDO) cheeses in France, and the Montbéliarde breed, the second French cow breed, represents $95 \%$ of the milking cows of Franche-Comté. Our purpose is to develop MIR equations by different approaches to predict CMP of the Montbéliarde cow milk and to compare their accuracies to qualify their potential usage for further research and development in this field.

\section{MATERIALS AND METHODS}

\section{Sample Collection and Reference Data}

Details concerning the sampling procedure and the reference data have already been described in Sanchez et al. (2018).

Sampling Criteria and Protocol. In the main, we sampled milks of 250 Montbéliarde cows located in 216 single breed commercial herds in Franche-Comté. The sampling was designed to maximize genetic diversity as well as variation in milk composition among the current Montbéliarde cattle population in the Franche-Comté region. Two criteria were used for this selection: the lactoprotein phenotypes based on the results of a previous study (Fang et al., 2016) and the lactation stage. Cows with rare alleles of lactoproteins were systematically collected. We planned to gather half of the 250 individual cow milk samples in January-March 2016 (indoor season) and half in April-June 2016 (outdoor season), and either from the morning milking $(2 / 5)$, the evening milking $(2 / 5)$, or the mixture of 2 successive milkings, in relative proportion $(1 / 5)$. Samples of fresh raw whole milk were collected under strict hygienic conditions, immediately cooled down at $4^{\circ} \mathrm{C}$, and analyzed within $24 \mathrm{~h}$. We divided each sample into 2 sub-samples. One $(25 \mathrm{~mL})$ sub-sample was preserved with Bronopol and taken to the laboratory (Lacolait, Roulans) to be analyzed by MIR spectroscopy using MilkoScan FT6000 (Foss, Hillerod, Denmark) and by Fossomatic FC counter (Foss) for SCC. We recorded fat, protein, lactose, and urea contents. The MIR spectra were stored. The second sub-sample $(1 \mathrm{~L})$ was analyzed for total viable counts $\left(\mathrm{cfu} / \mathrm{mL}\right.$ ) on plate count agar, $72 \mathrm{~h}$ at $30^{\circ} \mathrm{C}$ (ISO 4833-1 standard), titratable acidity, expressed as Dornic degree $\left({ }^{\circ} \mathrm{D}\right)$, and by reference methods for determin- 
ing CY (INRA, Poligny, France) and coagulation and acidification properties (ENILBIO, Poligny, France). Samples with SCC values above $10^{6} / \mathrm{mL}$ or cfu value above $10^{5} / \mathrm{mL}$ were discarded and replaced, as much as as possible, by new ones.

Coagulation Traits. Coagulation properties were measured with the Formoptic, adapted from a Formagraph (Foss) by Chr. Hansen (Horshom, Denmark) and ENILBIO (Poligny, France) to improve data computerization, as already described by Sanchez et al. (2018). In short, raw whole milk samples were adjusted in $\mathrm{pH}$ with lactic acid (20\%), coagulated with rennet at $32^{\circ} \mathrm{C}$ according to 1 of 2 models of cheese technology, for soft (SC) or pressed cooked (PCC) cheese. Both tests were made in duplicate. For SC, rennet extract (2.5 $\mu \mathrm{L} / 10 \mathrm{~mL}, 520 \mathrm{mg}$ of chymosin/L, Naturen-Chr. Hansen, Arpajon, France) was added at $\mathrm{pH}$ 6.45. For PCC, rennet extract $(1.4 \mu \mathrm{L} / 10 \mathrm{~mL}, 810 \mathrm{mg}$ of chymosin/L, Berthelot-ABIA, Beaune, France) was added at $\mathrm{pH}$ $6.60 \mathrm{pH}$ values of 6.45 and 6.60 are usually used for the renneting of unpressed-uncooked cheeses (including soft and blue cheeses) and pressed semi-cooked and cooked cheeses, respectively; $32^{\circ} \mathrm{C}$ is the temperature of renneting used for every type of cheese technology (Almena-Aliste and Mietton, 2014). With the Formoptic, an optical sensor measures the pendulum movement and converts this information into voltages. These measures are computerized, and a specific software program recreates the coagulation diagram (Troch et al., 2017). From the diagram of firmness (expressed in firmness index; $\mathbf{F I}=$ volts $\times 10)$ versus time $(\min )$, we registered the following coagulation traits (Figure 1):

1) Rennet coagulation time (RCT) to $0.5 \mathrm{FI}$ for $\mathrm{SC}$ $\left(\mathbf{R C T}_{\mathbf{S C}}\right)$ and PCC $\left(\mathbf{R C} \mathbf{T}_{\mathbf{P C C}}\right)$, in minutes,

2) Curd firmness after RCT for $\mathrm{SC}\left(\mathbf{a}_{\mathbf{S C}}\right)$ and PCC $\left(\mathbf{a}_{\mathrm{PCC}}\right)$, in FI units,

3) Curd firmness at 2 times $\mathrm{RCT}$ for $\mathrm{SC}\left(\mathbf{a} \mathbf{2}_{\mathrm{SC}}\right)$, in FI units,

4) Time to obtain $10 \mathrm{FI}$ from RCT for $\mathrm{SC}\left(\mathbf{K} \mathbf{1 0} \mathbf{S C}_{\mathbf{S C}}\right)$ and $\mathrm{PCC}\left(\mathbf{K} 1 \mathbf{1}_{\mathrm{PCC}}\right)$, in minutes,

5) The ratio of $\mathrm{K} 10$ to $\mathrm{RCT}$ for $\mathrm{SC}\left(\mathbf{K} \mathbf{1 0} / \mathbf{R C T}_{\mathbf{S C}}\right)$ and PCC $\left(\mathbf{K} 10 / \mathbf{R C T}_{\mathbf{P C C}}\right)$, and

6) The curd organization speed (slope of the curve at firmness $=10 \mathrm{FI})$ for $\mathrm{SC}\left(\mathbf{T G}_{\mathbf{1 0}}\right)$ and PCC (TG10 $\left.{ }_{\mathrm{PCC}}\right)$.

Repeatability was evaluated in SC conditions test over 10 replicates of a cow milk sample (a bulk skim milk, pasteurized at $74^{\circ} \mathrm{C} 20 \mathrm{~s}$ to which $\mathrm{CaCl}_{2}$ was added at $0.05 \mathrm{~g} / \mathrm{L}$ just after pasteurization, then adjusted in $\mathrm{pH}$ at 6.45 with lactic acid $20 \%$ ) calculating the standard deviation $\left(\mathrm{S}_{\mathrm{r}}\right)$ and the coefficient of variation $\left(\mathrm{CV}_{\mathrm{r}}\right)$ for each parameter. Average values and $\mathrm{CV}_{\mathrm{r}}$ were $13.6 \mathrm{~min}$ and $3.1 \%$ for RCT, 1.0 min and $4.7 \%$ for $\mathrm{K} 10,16.3 \mathrm{FI}$ and $2.8 \%$ for a, $22.4 \mathrm{FI}$ and $1.5 \%$ for a2, 0.53 and $4.9 \%$

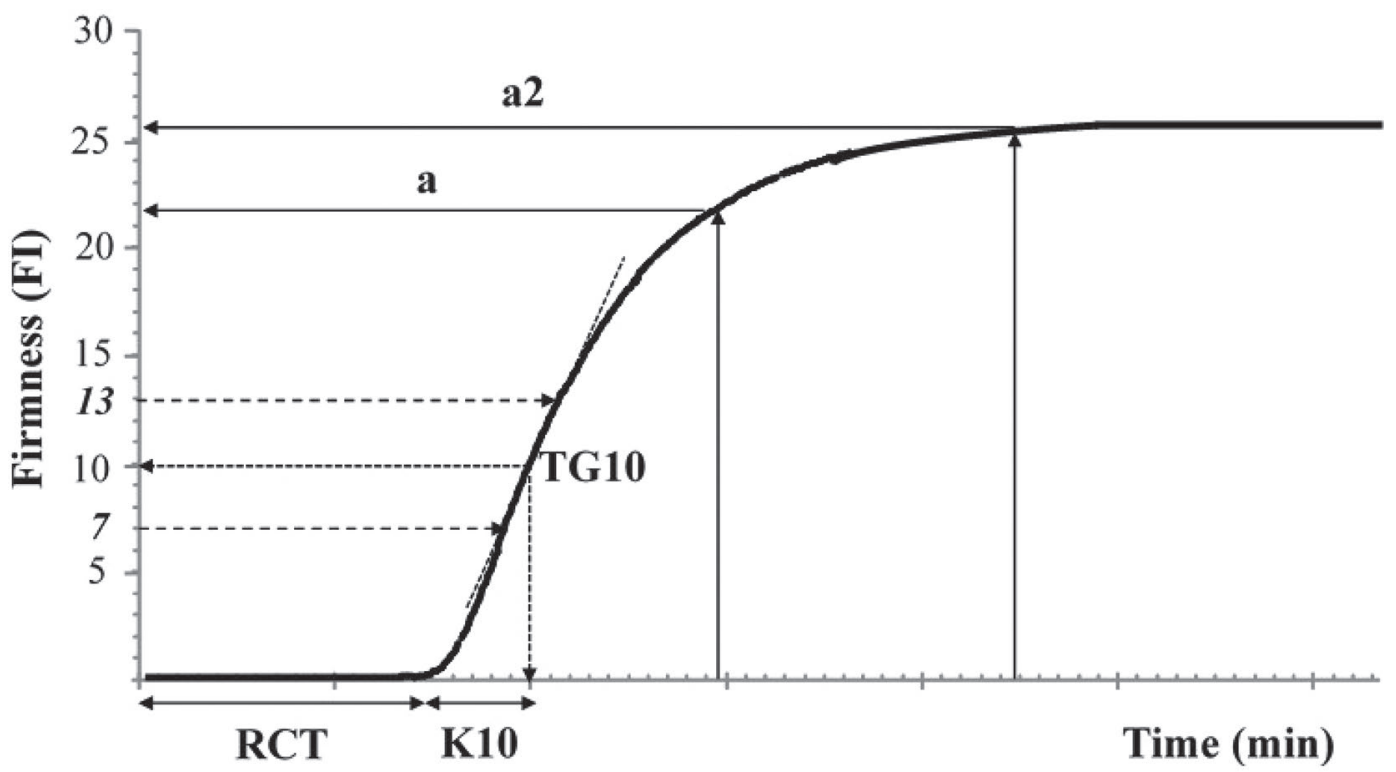

Figure 1. Formoptic data output showing the measured traits. RCT = rennet coagulation time (min); K10 = time to obtain 10 firmness index (FI) from RCT (min); a = curd firmness after RCT (FI); a2 = curd firmness at 2 times RCT (FI); TG10 = curd organization speed (slope of the curd at $10 \mathrm{FI} ; \mathrm{FI} / \mathrm{min})$; and FI $=$ volts $\times 10$. 
for $\mathrm{K} 10 / \mathrm{RCT}$, and 13.1 and $4.9 \%$ for TG10, respectively. We considered all $\mathrm{CV}_{\mathrm{r}}$ values acceptable.

Acidity Traits. The CINAC system (Corrieu et al., 1988) was used to assess the acidification properties of the milk by continuous measurement of the $\mathrm{pH}$ for 20 $\mathrm{h}$, in either SC or PCC conditions. Flasks of raw whole milk $(100 \mathrm{~mL})$ were inoculated $\left(5.10^{6}\right.$ to $10^{7} \mathrm{cfu} / \mathrm{mL}$ of milk) either with a mesophilic starter (Lactococcus lactis ssp. lactis SRTA 2006 strain) and submitted to a specific SC time/temperature combination, or with a thermophilic starter (Streptococcus thermophilus FTS 79 strain) and submitted to a specific PCC time/ temperature combination. We conducted the 2 tests in parallel on 2 systems. We used a reconstituted skim milk to monitor the starter's activity over time. We recorded the following cheese-specific traits:

1) Initial $\mathrm{pH}$ for $\mathrm{SC}\left(\mathbf{p H}_{\mathbf{0} \_\mathbf{S C}}\right)$ and $\mathrm{PCC}\left(\mathbf{p H}_{\mathbf{0} \_\mathbf{P C C}}\right)$, in $\mathrm{pH}$ units (upH),

2) Acidification rate from 170 to $230 \mathrm{~min}$ for PCC $\left(\mathbf{A R}_{170-230 m i n-\mathbf{P C C}}\right)$, in upH/hour,

3) $\mathrm{pH}$ at $10 \mathrm{~h}$ for PCC $\left(\mathbf{p H}_{\mathbf{1 0 h} \_\mathbf{P C C}}\right)$, in $\mathrm{upH}$,

4) Time to reach a decrease of $0.08 \mathrm{upH}$ from $\mathrm{pH}_{0}$ for $\mathrm{SC}\left(\mathbf{T} \boldsymbol{\Delta} \mathbf{p H}_{0.08 \_s C}\right)$, in hours,

5) Time from $\mathrm{pH} 6$ to $\mathrm{pH} 4.8$ for $\mathrm{SC}\left(\mathbf{T} \boldsymbol{\Delta} \mathbf{p} \mathbf{H}_{6-4.8} \_\mathbf{S C}\right)$, in hours,

6) Decrease of $\mathrm{pH}$ from 16 to $20 \mathrm{~h}$ for $\mathrm{SC}$ $\left(\Delta \mathrm{pH}_{16-20 \mathrm{~h}-\mathrm{sC}}\right)$, in upH, and

7) $\mathrm{pH}$ at $20 \mathrm{~h}$ for $\mathrm{SC}\left(\mathbf{p H}_{20 \mathrm{~h} \_s c}\right)$, in $\mathrm{upH}$.

Curd Yield Traits. Finally, laboratory CY were measured in duplicate according to a method adapted from Hurtaud et al. (1993). Rennet extract $810 \mathrm{mg}$ of chymosin/L (Berthelot-ABIA, Beaune, France) was added to raw whole milk samples $(50 \mathrm{~mL}$ in conical centrifuge tube at $\mathrm{pH} 6.6$ and $32^{\circ} \mathrm{C}$ ). One hour after rennet addition, the coagulum was cut with a homemade little cheese harp whose shape was perfectly adapted to the geometry of the bottom of the conical centrifuge tube, then centrifuged $\left(2,700 \times g, 15 \mathrm{~min}\right.$ at $\left.32^{\circ} \mathrm{C}\right)$. The supernatant (whey) was transferred by inversion to a clean-tared tube taking care not to disturb the pellet (curd) followed by pipetting to well recover all the whey. Milk, curd, and whey were weighed. We determined the DM of the milk and the whey (NF V04-342 standard), the protein content and fat content of the milk (MIR spectroscopy), and calculated the following CY:

$$
\text { Fresh CY in \%: CY } \mathbf{Y}_{\text {FRESH }}=100 \times\left(\frac{\mathrm{g} \text { of curd }}{\mathrm{g} \text { of milk }}\right),
$$

$\mathrm{CY}$ in DM in \%: $\mathbf{C Y}_{\mathrm{DM}}=100 \times\left(1-\frac{\mathrm{g} \text { of DM whey }}{\mathrm{g} \text { of DM milk }}\right)$, and
CY in protein and fat in grams per kilogram (the amounts of milk fat and protein required to obtain $1 \mathrm{~kg}$ of curd):

$$
\begin{gathered}
\mathbf{C Y}_{\text {FAT-PRot }}=(\mathrm{PC}+\mathrm{FC}) \times\left(\frac{\mathrm{g} \text { of milk }}{\mathrm{g} \text { of curd }}\right) \text {, where } \\
\mathrm{PC}=\text { protein content and } \mathrm{FC}=\text { fat content. }
\end{gathered}
$$

Repeatability was evaluated over 7 replicates of a bulk whole milk sample from a herd, calculating the standard deviation $\left(\mathrm{S}_{\mathrm{r}}\right)$ and the coefficient of variation $\left(\mathrm{CV}_{\mathrm{r}}\right)$. Means and $\mathrm{CV}_{\mathrm{r}}$ were 34.89 and $2.4 \%$ for $\mathrm{CY}_{\mathrm{FRESH}}$, and 65.07 and $0.9 \%$ for $\mathrm{CY}_{\mathrm{DM}}$, respectively. These CV values were comparable to those reported by Hurtaud et al. (1995).

\section{MIR Spectra and Prediction Models}

Mid-infrared spectra were collected on FT 6000 instrument (Foss) over the spectral range of 925 to $5,011 \mathrm{~cm}^{-1}$ (1,060 wavenumbers) and standardized by piecewise direct standardization, which matches slaveinstrument spectra on master-instrument spectra (Grelet et al., 2015). Only the informative wavelengths (446 wavelengths) were kept as data through the elimination of noisy areas induced by water absorption (i.e., 1,600 to $1,689 \mathrm{~cm}^{-1}$ and 3,008 to $5,011 \mathrm{~cm}^{-1}$ ), following the recommendation of the manufacturer of the MilkoScan FT6000. We developed prediction equations using different PLS or Bayesian approaches for all CMP traits (9 for rennet coagulation, 8 for acidification, and 3 for $\mathrm{CY}$ ). Models were fitted to spectral data expressed in transmittance. We tested the random forest (RF) method to select the most informative wavelengths for the prediction of CMP traits (Breiman, 2001), and the uninformative variable elimination (UVE) procedure proposed by Centner et al. (1996), as another method to remove uninformative wavelengths before PLS analysis (Cai et al., 2008; de los Campos et al., 2013b; Visentin et al., 2016). These methods (RF, UVE) were used as a preliminary step before PLS regression (RFPLS, UVEPLS). We operated Bayes A, Bayes B, Bayes C, and Bayes RR models to implement regression equations. These models differ in the form of the prior distribution assigned to the regression coefficients. In Bayes RR, coefficients are assigned Gaussian priors allowing an estimate shrinkage toward zero, which is homogeneous across coefficients. Bayes A assigns coefficients to a scaled $t$ density leading to an estimate shrinkage size-of-effect dependent. Bayes B and C are finite mixture prior methods. Either they have a point of mass at zero with a scaled $t$ slab (Bayes B) or a point of mass at zero with a Gaussian slab (Bayes C). The priors used in these 2 methods lead to variable selection (Perez and de los Campos, 2014; Ferragina et al., 2015). 
The possible presence of outliers was checked. Outliers were discarded from reference data using the Grubbs test (Grubbs, 1969). For spectral data, Mahalanobis distance was calculated after performing PCA analysis. A spectrum was considered as outlier when exhibiting a Mahalanobis distance from the population centroid greater than 3. In our case, one outlier spectrum was identified and deleted. Also, samples for which the difference between the reference and the predicted value was greater than 2.5 times the standard error of calibration were considered as outliers (T-outliers) and deleted (Soyeurt et al., 2011). This outlier technique was used with caution. Less than $5 \%$ of the total samples in our study were deleted. Exclusion of T-outliers could improve the calibration; however, enough samples should remain in the calibration set to avoid significant reduction of representativeness in the reduced data set.

Both PLS and Bayesian models were developed with $\mathrm{k}$-fold cross-validation $(\mathrm{k}=10)$. The method exhibiting the best performances was assessed in external validation by randomly dividing the initial data set into the calibration data set ( $70 \%$ of the entire data set) and validation data set (the remaining $30 \%$ of the entire data set). For PLS regressions, the optimal number of latent variables $(\# \mathbf{L})$ was defined by minimizing the root mean square error of prediction.

To qualify the equations, we compared the mean and standard deviation (SD) of the predicted and measured values in both calibration and validation set. We calculated the coefficient of determination $\left(\mathbf{R}^{2}\right)$, the residual standard deviation $\left(\mathbf{S}_{\mathbf{y}, \mathrm{x}}\right)$, the relative error $\left(\mathbf{R S}_{\mathbf{y , x}}\right.$ in $\%$ ), and the ratio of performance to deviation (RPD $=$ ratio of standard deviation of the reference data to standard error of prediction) in cross-validation and external validation. Equations with the highest $\mathrm{R}^{2}$ and $R P D$ values and the lowest $R S_{y, x}(\%)$ value are regarded as being the most accurate. Karoui et al. (2006) and Coppa et al. (2010) used the $\mathrm{R}^{2}$ value to define 4 classes of robustness: poor $\left(\mathrm{R}^{2}<0.66\right)$, approximate $(0.66<$ $\left.\mathrm{R}^{2}<0.81\right)$, good $\left(0.82<\mathrm{R}^{2}<0.90\right)$, and excellent $\left(\mathrm{R}^{2}\right.$ $\geq 0.91$ ). Equations with $\mathrm{RPD}>2$ enable predictions with good accuracy (De Marchi et al., 2013; Gottardo et al., 2015). Viscarra Rossel et al. (2006) defined 6 classes more specifically: very poor $(\mathrm{RPD}<1)$, poor $(1<\mathrm{RPD}<1.4)$, fair $(1.4<\mathrm{RPD}<1.8)$, good $(1.8$ $<\mathrm{RPD}<2)$, very good $(2<\mathrm{RPD}<2.5)$, and excellent $(\mathrm{RP}>2.5)$. All computations were done using $\mathrm{R}$ software (version 3.2.3, https://r-project.org/).

\section{RESULTS}

\section{Descriptive Statistics}

Among the 250 milk samples, 121 were collected during the indoor season (PI) and 129 during the out- door season (PO): 98 from the morning milking (47 in PI; 51 in PO), 99 from the evening milking (50 in PI; 49 in PO), and 53 from the mixture of 2 successive milkings (24 in PI; 29 in PO). Descriptive statistics for individual milk data recording are presented in Table 1. In both collection seasons, milks at sampling date were obtained from multiparous cows in various stages of lactation (14-419 d), producing milk yields (8.2$43.1 \mathrm{~kg} / \mathrm{d})$ with various fat $(1.78-6.03 \%)$ and protein $(2.42-4.97 \%)$ levels. Ranges of lactation stages were comparable between the 2 sampling periods except that 4 cows were in extended lactation (DIM $>380 \mathrm{~d}$ ) in PO. Fat and protein averaged 3.80 and $3.24 \%$, respectively, and were somewhat lower in PO for fat, but similar in both periods for protein. The coefficient of variation $(\mathbf{C V})$ of these 2 traits was high, and fat was almost double $(19.9 \%)$ that of protein $(11.3 \%)$ regardless of period. These results were consistent with the data recording of the Montbéliarde cattle population at the same periods in the Franche-Comté region. We also observed a random distribution of fat and protein contents whatever the period and the milking sample (Supplemental Figure S1; https://doi.org/10.3168/jds .2019-16320). The diversity of $\alpha_{\mathrm{S} 1}-\beta-\kappa-\mathrm{CN}$ haplotypes of the 250 sampled cows $\left(\mathrm{CA}^{2} \mathrm{~A}, \mathrm{BA}^{2} \mathrm{~A}, \mathrm{BA}^{1} \mathrm{~A}, \mathrm{BBA}\right.$, $\mathrm{BA}^{1} \mathrm{~B}, \mathrm{BA}^{2} \mathrm{~B}, \mathrm{BIB}, \mathrm{BBB}, \mathrm{BIA}$, and $\mathrm{BAE}$ ) and their frequencies are provided in Supplemental Table S1 (https://doi.org/10.3168/jds.2019-16320). The SCS, total viable counts, and urea content averaged 2.21, $3.38 \log (\mathrm{cfu} / \mathrm{mL})$, and $16.3 \mathrm{mg} / 100 \mathrm{~g}$, respectively. Means and CV of these traits were quite similar in both periods. Composition traits had good variability (CV from $11.3 \%$ for protein to $29.7 \%$ for urea), with the exception of $\mathrm{pH}(\mathrm{CV}=0.8 \%)$ and lactose $(\mathrm{CV}=$ $4.4 \%$ ). These results show that we collected a wide variety of quite good quality milks as expected from the sampling protocol, covering the variability expected in the population.

Consequently, CMP reference data presented a high degree of variability in most cases as indicated by their descriptive statistics (Table 2). The CV values ranged from $9.9 \%\left(\mathrm{CY}_{\mathrm{DM}}\right)$ to $43.3 \%$ (TG10 ${ }_{\mathrm{PCC}}$ ) among $\mathrm{CY}$ and coagulation traits. Average values for $\mathrm{RCT}_{\mathrm{SC}}$, $\mathrm{RCT}_{\mathrm{PCC}}, \mathrm{a}_{\mathrm{SC}}$, and $\mathrm{a}_{\mathrm{PCC}}$ were $17.0 \mathrm{~min}(\mathrm{CV}=20.9 \%)$, $31.9 \min (\mathrm{CV}=22.9 \%), 18.8 \mathrm{FI}(\mathrm{CV}=17.5 \%)$, and 18.4 FI $(\mathrm{CV}=17.5 \%)$, respectively. The variability of the Formoptic coagulation traits was in the same order of magnitude for traits measured in SC and PCC conditions. Except for a few traits such as some specific values of $\mathrm{pH}\left(\mathrm{pH}_{0 \_ \text {SC }}, \mathrm{pH}_{0 \_\mathrm{PCC}}, \mathrm{pH}_{20 \mathrm{~h} \_\mathrm{SC}}, \mathrm{pH}_{10 \mathrm{~h} \_\mathrm{PCC}}\right)$ that were expected to be less variable, acidification traits varied considerably, with $\mathrm{CV}$ ranging from 24.3 for $\mathrm{T} \Delta \mathrm{pH}_{6-4.8-\mathrm{SC}}$ to $75.3 \%$ for $\Delta \mathrm{pH}_{10-20 \mathrm{~h} \_\mathrm{SC}}$. These results suggested that the variability of our data set was large 


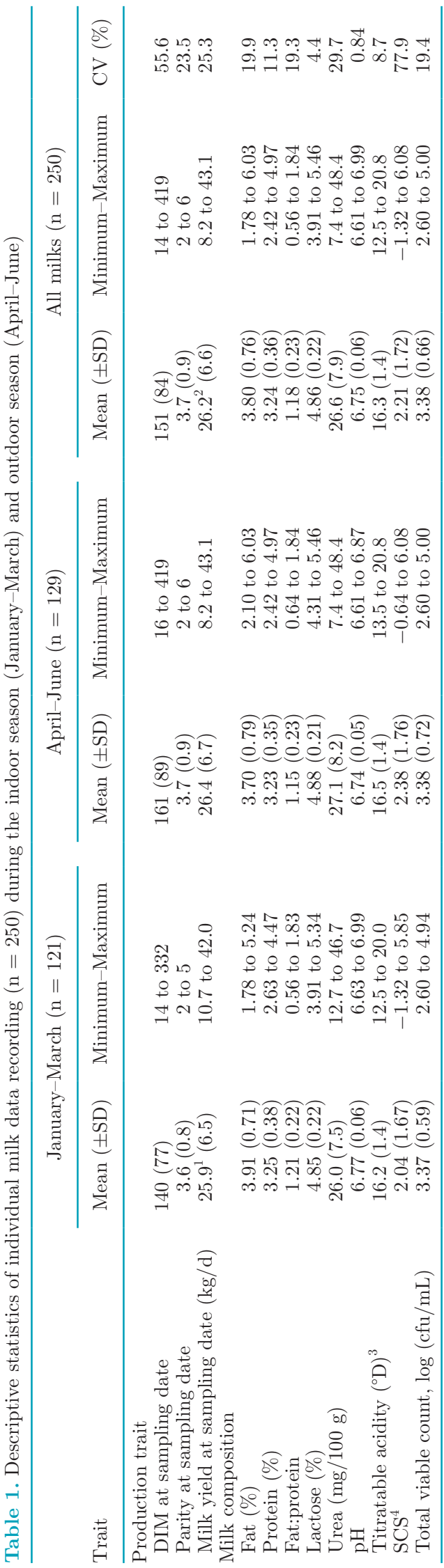

enough to develop prediction models for CMP traits using MIR spectra.

\section{Fitting Statistics: Comparison of Models in Cross-Validation}

Table 3 summarizes, for each trait, the performance criteria $\left(\mathrm{R}^{2}\right.$ and $\left.\mathrm{RS}_{\mathrm{y}, \mathrm{x}}\right)$ in cross-validation of the 7 different tested methods (PLS, RFPLS, UVEPLS, Bayes A, Bayes B, Bayes C, and Bayes RR).

Accuracy of PLS Regression Models With and Without Variable Selection. Regardless the regression models, the most accurate results were achieved, with 9 to $14 \mathrm{\# L}$, for 2 measurements of $\mathrm{CY}\left(\mathrm{CY}_{\mathrm{DM}}\right.$ : $\left.\mathrm{R}^{2}>0.9 ; \mathrm{CY}_{\mathrm{FRESH}}: \mathrm{R}^{2} \approx 0.85\right), 5$ coagulation traits $\left(\mathrm{a}_{\mathrm{SC}}\right.$ and $\mathrm{a}_{\mathrm{PCC}}: \mathrm{R}^{2} \geq 0.78 ; \mathrm{a} 2_{\mathrm{SC}}: \mathrm{R}^{2} \geq 0.70 ; \mathrm{K} 10 / \mathrm{RCT}_{\mathrm{SC}}$ and $\left.\mathrm{K} 10 / \mathrm{RCT}_{\mathrm{PCC}}: \mathrm{R}^{2} \geq 0.61\right)$ and only one acidification trait $\left(\mathrm{pH}_{0 \_\mathrm{PCC}}: \mathrm{R}^{2} \geq 0.61\right)$. Prediction equations showed similar performances for $\mathrm{a}_{\mathrm{SC}}$ and $\mathrm{a}_{\mathrm{PCC}}$, and for $\mathrm{K} 10 / \mathrm{RCT}_{\mathrm{PCC}}$ and $\mathrm{K} 10 / \mathrm{RCT}_{\mathrm{PCC}}$, except that $\# \mathrm{~L}$ for $\mathrm{K} 10 / \mathrm{RCT}_{\mathrm{PCC}}$ was one-third lower $(\# \mathrm{~L}=9)$ than $\# \mathrm{~L}$ for $\mathrm{K} 10 / \mathrm{RCT}_{\mathrm{SC}}(\# \mathrm{~L}=14)$. Prediction models for $\mathrm{CY}_{\text {FAT-PROT }}\left(\mathrm{R}^{2}<0.6\right)$ and all other traits were poor: 6 coagulation traits, including RCT for both PCC $\left(\mathrm{R}^{2}\right.$ $\leq 0.41)$ and $\mathrm{SC}\left(\mathrm{R}^{2} \leq 0.32\right)$ and 7 acidification traits $\left(0.04<\mathrm{R}^{2}<0.45\right)$.

For $\mathrm{CY}_{\mathrm{FRESH}}$ and $\mathrm{CY}_{\mathrm{DM}}$ traits, variable selection by RFPLS or UVEPLS methods did not significantly improve the prediction results compared with the standard PLS. Results were slightly better with UVEPLS for $\mathrm{CY}_{\mathrm{FRESH}}\left(\mathrm{R}^{2}=0.86, \mathrm{RS}_{\mathrm{y}, \mathrm{x}}=9 \%\right)$ and with RFPLS for $\mathrm{CY}_{\mathrm{DM}}\left(\mathrm{R}^{2}=0.92, \mathrm{RS}_{\mathrm{y}, \mathrm{x}}=3 \%\right)$. Similarly, among coagulation traits, variable selection before PLS did not show any significant improvement of the prediction performances for the 5 best-predicted traits $\left(\mathrm{a}_{\mathrm{PCC}}, \mathrm{a}_{\mathrm{SC}}\right.$, $\mathrm{a} 2_{\mathrm{SC}}, \mathrm{K} 10 / \mathrm{RCT}_{\mathrm{SC}}$, and $\left.\mathrm{K} 10 / \mathrm{RCT}_{\mathrm{PCC}}\right)$. The PLS models for TG10 gave poor results, but in this particular case, an improvement of the model was achieved with the RFPLS method for TG10 ${ }_{\mathrm{sc}}\left(\mathrm{R}^{2}=0.61\right)$ and TG10 $\mathrm{PCC}$ $\left(\mathrm{R}^{2}=0.60\right)$ with a decrease in $\# \mathrm{~L}(\# \mathrm{~L}=9)$; however, it was still insufficient with respect to the quality of the prediction. Concerning the acidification traits, we obtained the best predictions for the $\mathrm{pH}_{0 \_\mathrm{PCC}}$ and $\mathrm{pH}_{0 \_\mathrm{SC}}$ traits. We observed no improvement due to variable selection for $\mathrm{pH}_{0 \_\mathrm{SC}}$, but a better $\mathrm{R}^{2}$ (0.44 with UVEPLS instead of 0.35 with PLS only) for $\mathrm{pH}_{0 \_ \text {PCC }}$, whereas \#L remained high and unchanged for both traits (\#L $>15)$.

Accuracy of Bayesian Models. With Bayesian regression, we observed the best prediction performances with models obtained for $\mathrm{CY}_{\mathrm{DM}}\left(0.86<\mathrm{R}^{2}<0.87\right.$, $\left.\mathrm{RS}_{\mathrm{y}, \mathrm{x}}=4 \%\right)$ and $\mathrm{CY}_{\mathrm{FRESH}}\left(0.77<\mathrm{R}^{2}<0.79, \mathrm{RS}_{\mathrm{y}, \mathrm{x}}\right.$ $=11-12 \%)$. In comparison, prediction performances for $\mathrm{CY}_{\text {FAT-PROT }}$ were quite bad $\left(\mathrm{R}^{2}<0.47\right)$. Among 
Table 2. Descriptive statistics of cheese-making property traits obtained by reference methods

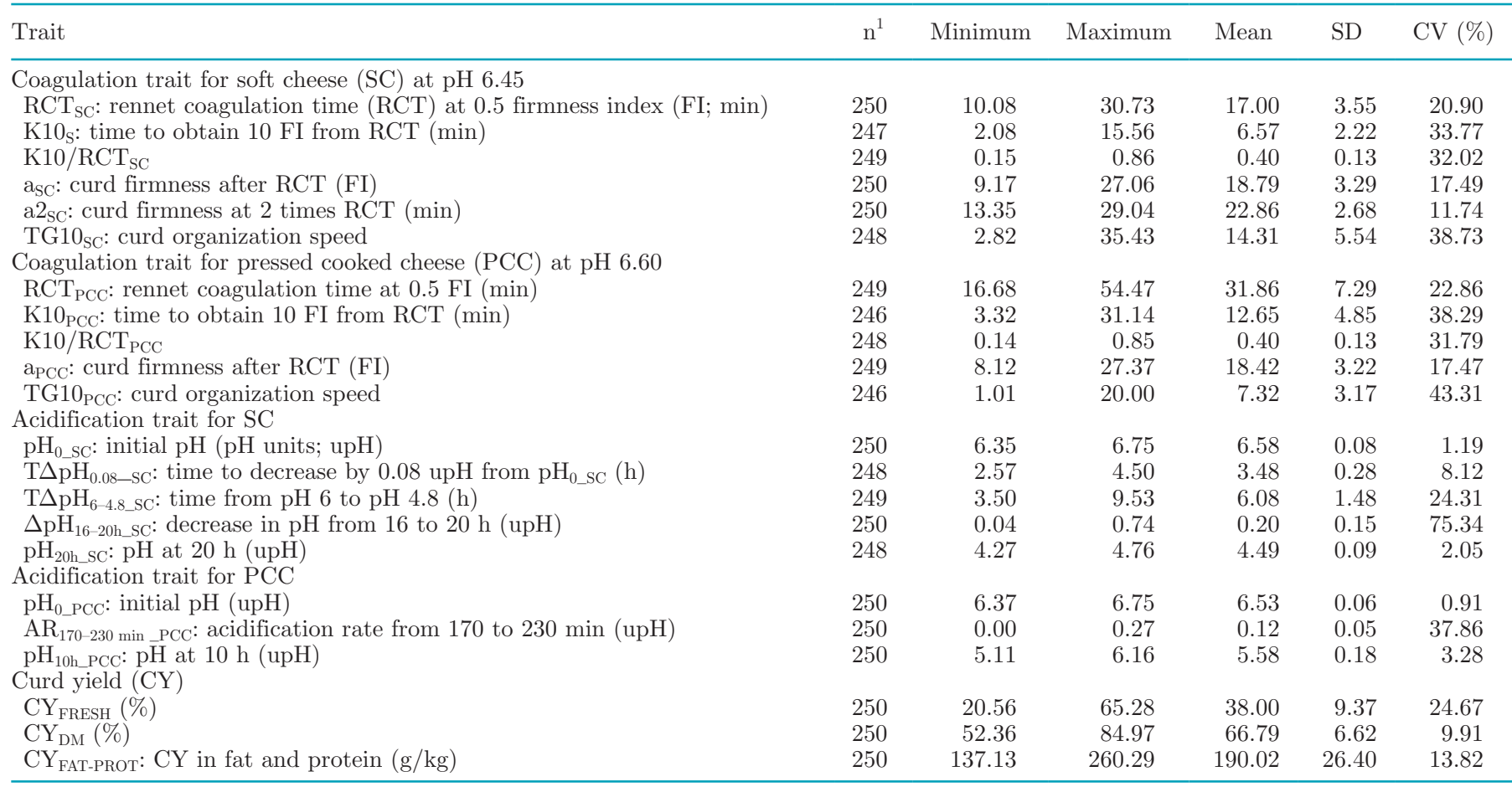

${ }^{1}$ Number of samples after removing outliers using Grubbs (1969) test.

coagulation traits, the best results were reached both for a $\left(\mathrm{a}_{\mathrm{sc}}: 0.56<\mathrm{R}^{2}<0.66, \mathrm{RS}_{\mathrm{y}, \mathrm{x}}=12-13 \%\right.$; $\mathrm{a}_{\mathrm{PCC}}$ : $\left.0.54<\mathrm{R}^{2}<0.64, \mathrm{RS}_{\mathrm{y}, \mathrm{x}}=11-13 \%\right)$ and a2 $\left(\mathrm{a} 2_{\mathrm{sc}}: 0.53\right.$ $\left.<\mathrm{R}^{2}<0.58, \mathrm{RS}_{\mathrm{y}, \mathrm{x}}=8 \%\right)$, then for K10/RCT $(\mathrm{K} 10 /$ $\mathrm{RCT}_{\mathrm{PCC}}: 0.45<\mathrm{R}^{2}<0.59 ; \mathrm{K} 10 / \mathrm{RCT}_{\mathrm{SC}}: 0.39<\mathrm{R}^{2}<$ 0.56). For others traits, results showed that Bayesian models applied to our set of spectra were not powerful, given calibration equations of bad quality $\left(0.00<\mathrm{R}^{2}<\right.$ $0.39)$, notably for both RCT traits $\left(\mathrm{R}^{2} \leq 0.06\right.$ and $\mathrm{R}^{2}$ $\leq 0.11$ for $\mathrm{RCT}_{\mathrm{PCC}}$ and $\mathrm{RCT}_{\mathrm{SC}}$, respectively). Among the best-predicted traits, except CY traits, significant differences appeared between the predictive ability of Bayesian models, depending on the nature of the traits. For the curd firmness traits, Bayes B performed best whereas Bayes $\mathrm{C}$ performed worst $\left(\mathrm{R}^{2}\right.$ values, 0.05 to 0.13 point lower). For the K10/RCT and TG10 traits, Bayes $\mathrm{C}$ models exhibited less accuracy than Bayes A, B, and RR models did. By comparing the different Bayesian methods used in our study, we found that Bayes RR led to better results in most cases except for the curd firmness traits where Bayes B might perform better.

Bayesian Models Compared with PLS Regressions. We compared the performances of the PLS and Bayesian regressions models based on spectra analyses cleared of the water absorption regions. Although we achieved some good results with Bayesian regression models for the prediction of CY and curd firmness traits, this approach was less accurate than PLS regression on 446 wavelengths. For each tested trait, all PLS regression models yielded higher $\mathrm{R}^{2}$ and lower $\mathrm{S}_{\mathrm{y}, \mathrm{x}}$ compared with any Bayesian model used. The maximum difference in $\mathrm{R}^{2}$ between the PLS and Bayesian methods was as high as 0.49 points for $\mathrm{pH}_{0 \_\mathrm{PCC}}$. For the CY traits, the differences between the performance parameters of Bayesian and PLS predictions were more pronounced for $\mathrm{CY}_{\mathrm{FRESH}}$ than $\mathrm{CY}_{\mathrm{DM}}$. By using the Bayesian models, the average $\mathrm{R}^{2}$ decreased from 0.85 to 0.78 and from 0.91 to 0.86 , and the average $S_{y, x}$ increased from 9 to $12 \%$ and from 3 to $4 \%$ for $\mathrm{CY}_{\mathrm{FRESH}}$ and $\mathrm{CY}_{\mathrm{DM}}$, respectively. The prediction of $\mathrm{CY}_{\mathrm{FAT} \text {-PROT }}$ reached a maximum $R^{2}$ value 0.12 to 0.13 points higher for PLS in comparison with Bayesian methods. The $\mathrm{R}^{2}$ values obtained with PLS for the best-predicted coagulation traits were largely above the $\mathrm{R}^{2}$ means calculated from the Bayesian prediction models. The differences between the best $R^{2}$ values were particularly marked for the curd firmness traits. The PLS $\mathrm{R}^{2}$ yielded 0.14 and 0.12 points more for $\mathrm{a}_{\mathrm{SC}}$ and $\mathrm{a}_{\mathrm{PCC}}$, respectively, when compared with the Bayesian $\mathrm{R}^{2}$, with a lower $\mathrm{S}_{\mathrm{y}, \mathrm{x}}$ (8 vs. 13\%). When using Bayesian models for other coagulation traits, prediction performances decreased a lot more for the least well predicted traits (decrease of $\mathrm{R}^{2}$ from 0.22 to 0.41 points for RCT, K10, and TG10) 


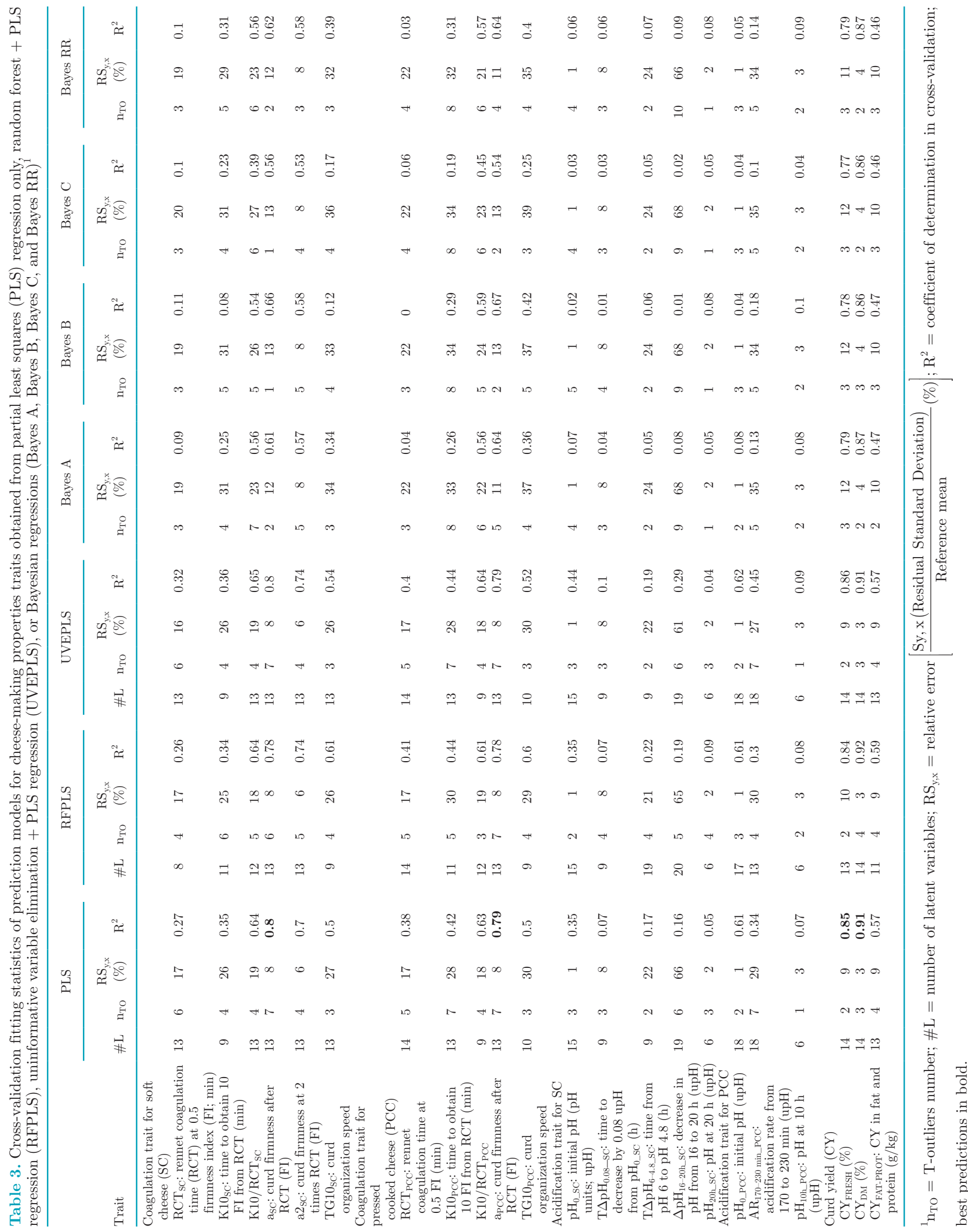

Journal of Dairy Science Vol. 102 No. 8, 2019 
than for K10/RCT (decrease of $\mathrm{R}^{2}$ from 0.04 to 0.11 points). For all acidification traits including $\mathrm{pH}_{0}\left(\mathrm{R}^{2} \leq\right.$ 0.08), the Bayesian methods showed very bad results ( $\mathrm{R}^{2}$ between 0.01 and 0.19 ).

\section{PLS Regressions in External Validation}

Because PLS methods gave the best results with our data set, we used this approach in a second step for developing calibration equations with external validation.

The mean and SD of the CMP traits in the calibration and validation data sets were similar. The PLS statistics of calibration and external validation sets are summarized in Table 4. The optimal \#L ranged from 9 to 14 for most traits except for the acidification traits (\#L either as low as 6 or as high as 19). As expected, the $\mathrm{R}^{2}$ values in the independent data sets (validation sets) were lower than those of the calibration $R^{2}$. In most case, the $R^{2}$ in external validation was 10 to 20 percentage points less than the calibration $\mathrm{R}^{2}$ value as already observed (Ferragina et al., 2015). The most accurate predictions were achieved in the calibration data set with 14 \#L for $\mathrm{CY}_{\mathrm{DM}}$ and $\mathrm{CY}_{\mathrm{FRESH}}\left(\mathrm{R}^{2}\right.$ of 0.92 and 0.89 , respectively) or $13 \# \mathrm{~L}$ for $\mathrm{a}_{\mathrm{SC}}$, $\mathrm{a}_{\mathrm{PCC}}$ and $\mathrm{a} 2_{\mathrm{SC}}\left(\mathrm{R}^{2}\right.$ of $0.85,0.84,0.82$, respectively) followed by $\mathrm{K} 10 / \mathrm{RCT}$ or TG10, $\mathrm{pH}_{0 \_ \text {PCC }}$, and $\mathrm{CY}_{\text {FAT-PROT }}$ with $\mathrm{R}^{2}$ in the calibration set ranging from 0.62 to 0.76 . For other traits, the prediction accuracy of the calibration models was poor $\left(\mathrm{R}^{2}\right.$ between 0.13 and 0.59$)$. In the external validation data set, we obtained excellent predictions for $\mathrm{CY}_{\mathrm{DM}}\left(\mathrm{R}^{2}=0.91, \mathrm{RS}_{\mathrm{y}, \mathrm{x}}=3 \%, \mathrm{RPD}=3.27\right)$ and they remained good in robustness and accuracy for $\mathrm{CY}_{\mathrm{FRESH}}$ $\left(\mathrm{R}^{2}=0.82, \mathrm{RS}_{\mathrm{y}, \mathrm{x}}=10 \%, \mathrm{RPD}=2.36\right)$. For coagulation traits, the best predictions in external validation were achieved for $\mathrm{a}_{\mathrm{SC}}\left(\mathrm{R}^{2}=0.67, \mathrm{RS}_{\mathrm{y}, \mathrm{x}}=9 \%, \mathrm{RPD}=1.73\right)$ and for $\mathrm{a}_{\mathrm{PCC}}\left(\mathrm{R}^{2}=0.63, \mathrm{RS}_{\mathrm{y}, \mathrm{x}}=10 \%, \mathrm{RPD}=1.62\right)$, then for $\mathrm{a}_{2 \mathrm{SC}}\left(\mathrm{R}^{2}=0.59, \mathrm{RS}_{\mathrm{y}, \mathrm{x}}=7 \%, \mathrm{RPD}=1.55\right)$. For all other CMP predictions, accuracy in external validation was fair or very poor including $\mathrm{K} 10 / \mathrm{RCT}$, TG10, $\mathrm{CY}_{\text {FAT-PROT }}$, and $\mathrm{pH}_{0 \_ \text {PCC }}$ for which $\mathrm{R}^{2}$ varied from 0.48 to 0.58 and RPD values were below 1.5. On average, prediction models tended to be unbiased except for $\mathrm{CY}_{\text {FAT-PROT. We }}$ checked the prediction scores given by the 4 best PLS models $\left(\mathrm{CY}_{\mathrm{FRESH}}, \mathrm{CY}_{\mathrm{DM}}\right.$, a $\mathrm{a}_{\mathrm{SC}}$, and $\mathrm{a}_{\mathrm{PCC}}$ ) with the observed values. The scatter plots for these 4 traits show good predictions of the regression models with a low degree of dispersion (Figure 2). The linear regression lines $(y=a x+b$, solid red line) of the reference values as a function of the predicted values are well merged with the first bisector $(\mathrm{y}=\mathrm{x}$, dashed blue line), which clearly indicates the exactness of the calibration equations for these traits.

\section{DISCUSSION}

\section{Standard Measurements and Quality of MIR Prediction for CMP Traits}

Curd yield and most coagulation traits of our data set had a comparable level and range of variation to those observed in other studies (Ferragina et al., 2015; Bonfatti et al., 2016; Visentin et al., 2016). This was not actually the case for RCT. We performed the coagulation tests after $\mathrm{pH}$ adjustment of the milk samples to mimic the $\mathrm{pH}$ at renneting in soft and pressed cooked cheese-making, and the variability of the RCT trait was reduced compared with data in other studies. Consequently, it was more difficult to establish good predictions of this trait and we obtained prediction models with poor accuracy $\left(0.09<\mathrm{R}^{2}<0.41\right)$ compared with models in other studies $\left(0.62<\mathrm{R}^{2}<0.69\right.$; De Marchi et al., 2009; Bonfatti et al., 2016). It is also important to underline that unlike most studies, we measured the curd firmness after RCT and not $30 \mathrm{~min}$ after rennet addition. Thus, under these particular test conditions, we could achieve the maximum curd firmness because this parameter is independent of the coagulation time. This explains why our measurements have introduced major differences compared with other studies. Other CMP traits than the RCT trait were also poorly estimated. For some, it is possible to come up with some explanations. Among CY traits, $\mathrm{CY}_{\text {FAT-PROT }}$ has shown fair estimation $\left(\mathrm{R}^{2}<0.6\right)$ in probable relation to how it was calculated. Indeed, the reference values take into account the lactose retained in the curd mass, contrary to the milk where the protein and fat are only considered, and in addition, more weighings could have generated more uncertainty. Expecting that the fine composition of the milk would influence the acidification aptitude of individual milk samples, we studied the acidification traits by MIR spectroscopy for the first time. We can assume that their molecular bases for MIR predictions are succinct. They are metabolic rather than biochemical traits, depending on the growth of bacterial cells. The initial $\mathrm{pH}$ value $\left(\mathbf{p H}_{\mathbf{0}}\right)$ corresponds to the $\mathrm{pH}$ value of the milk samples immediately after starter addition. On average, it was slightly different in soft cheese $\left(\mathrm{pH}_{0 \_ \text {SC }}\right)$ and pressed cooked cheese $\left(\mathrm{pH}_{0 \_\mathrm{PCC}}\right)$ conditions. This is due to the difference in $\mathrm{pH}$ of the 2 specific starter inoculums, which according to the 2 tested conditions have modified a little differently the $\mathrm{pH}$ of the milk samples at the start of the acidification test. However, $\mathrm{pH}_{0}$ that is very close to the $\mathrm{pH}$ value of the milk sample remains the only acidification trait closely linked with the buffering capacity of milk, which in turns depends on milk composition, and for which it 


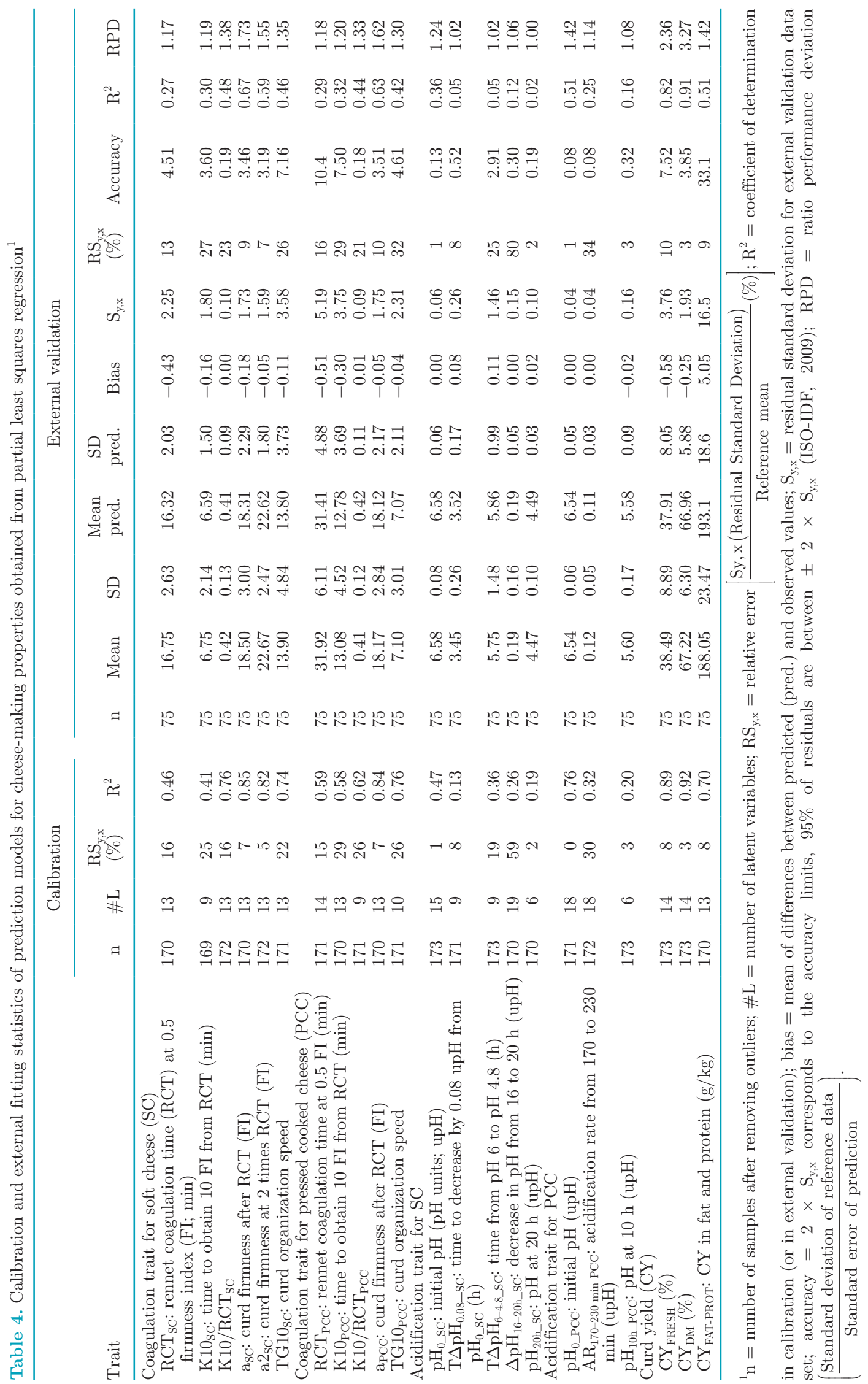


was possible to develop predictive models with a satisfactory degree of accuracy, as for milk pH (De Marchi et al., 2009; Visentin et al., 2015; Bonfatti et al., 2016; Manuelian et al., 2017).

As an expected outcome of our coagulation testing conditions, predictive models developed for $\mathrm{a}_{\mathrm{SC}}$ and $\mathrm{a}_{\mathrm{PCC}}$ or $\mathrm{K} 10 / \mathrm{RCT}_{\mathrm{SC}}$ and $\mathrm{K} 10 / \mathrm{RCT}_{\mathrm{PPC}}$ presented similar accuracies for the different approaches used in this study. The same applies for TG10 $\mathrm{SC}$ and TG10 $0_{\mathrm{PCC}}$, which indicate (as K10/RCT) how fast the curd is or- ganizing. At a given $\mathrm{pH}$, the flocculation time and the gelling organization/contraction depend on the coagulant dose and the temperature, respectively. Indeed, in our testing conditions, where the temperature was fixed $\left(32^{\circ} \mathrm{C}\right)$ and the amounts of chymosin were close enough $(130 \mu \mathrm{g} / 10 \mathrm{~mL}$ of milk in SC conditions vs. $113 \mu \mathrm{g} / 10$ $\mathrm{mL}$ of milk in PCC conditions), the main difference by performing the tests was the $\mathrm{pH}(6.45$ and 6.60 in $\mathrm{SC}$ and PCC conditions, respectively). Thus, the small difference in rennet extract and a difference of $0.15 \mathrm{upH}$ (a) CY FRESH

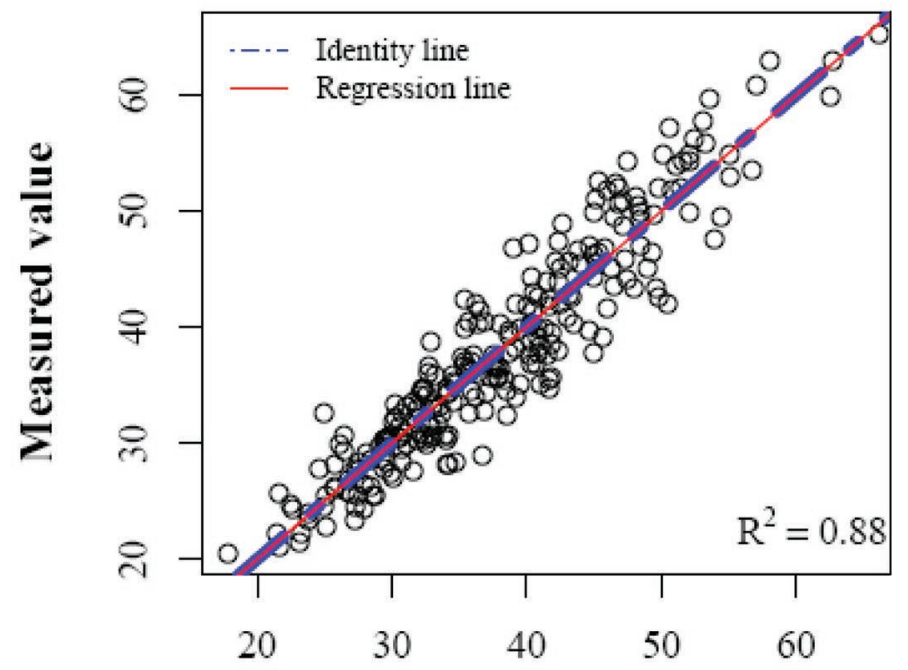

(c) apcc

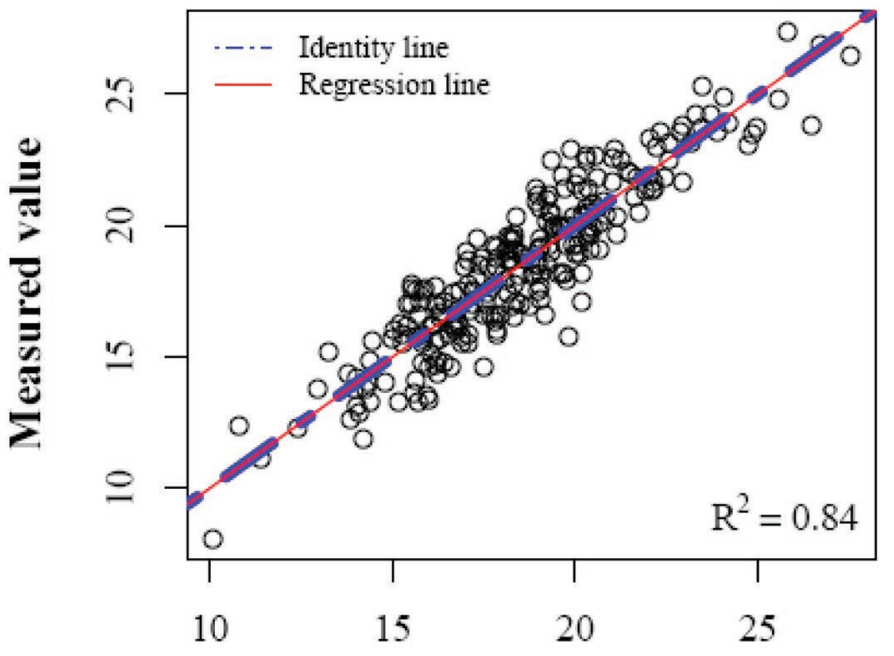

Predicted value (b) $\mathrm{CY}_{\mathrm{DM}}$

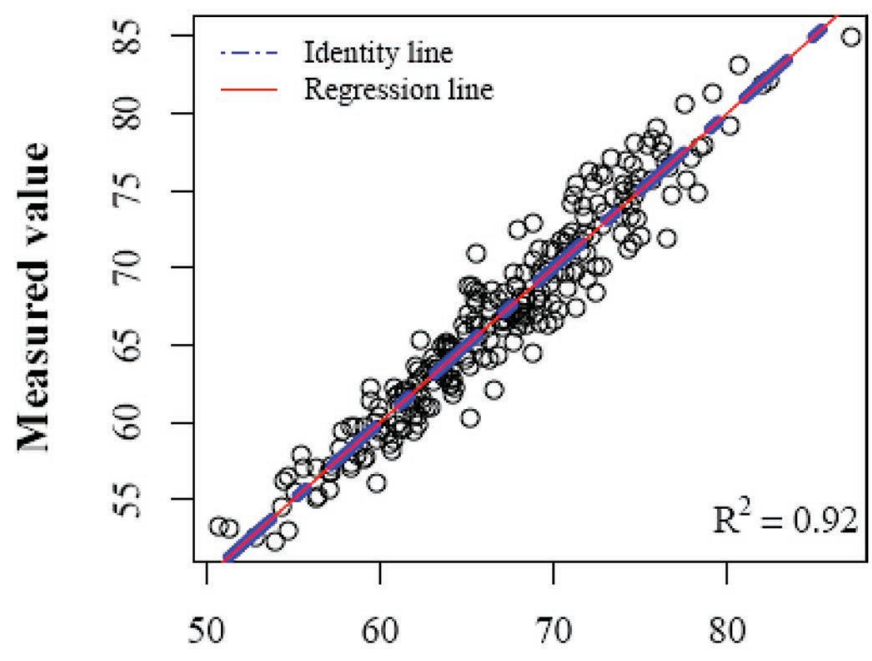

(d) asc

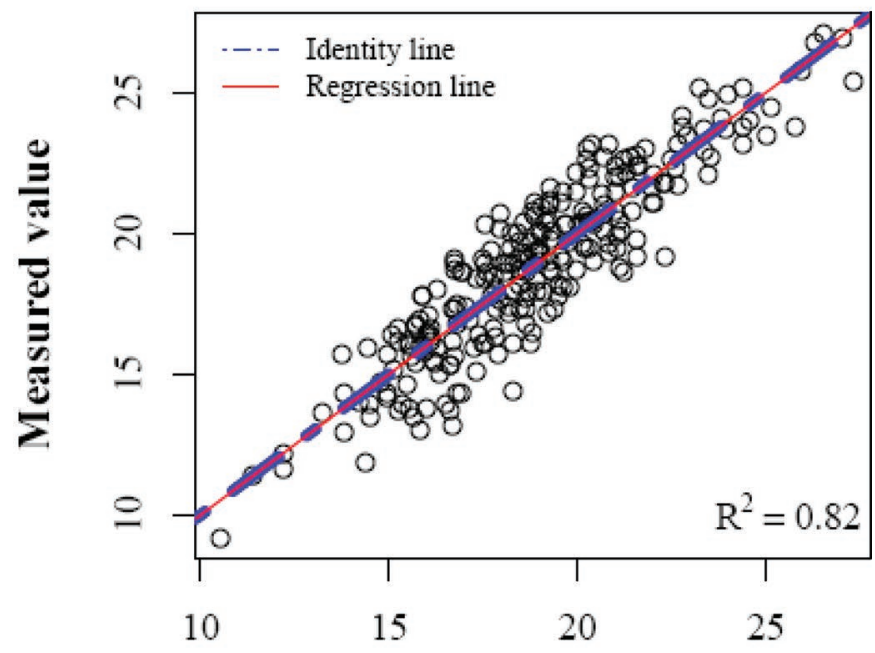

Predicted value

Figure 2. Scatter plots of reference (y-axis) versus predicted (x-axis) values for the best-predicted cheese-making traits using a partial least squares model obtained with the final equation. (a) $\mathrm{CY}_{\mathrm{FRESH}}=$ fresh curd yield (\%); (b) $\mathrm{CY}_{\mathrm{DM}}=$ curd yield in DM (\%); (c) a $\mathrm{PCC}=$ curd firmness after rennet coagulation time (RCT) in pressed cooked cheese conditions of rennet coagulation, firmness index $(\mathrm{FI}) ;(\mathrm{d})$ asC $=$ curd firmness after $\mathrm{RCT}$ in soft cheese conditions of rennet coagulation $(\mathrm{FI})$; and FI $=$ volts $\times 10$. Solid red line: regression line; dashed blue line: first bisector. 
have led to $\mathrm{RCT}_{\mathrm{PCC}}$ and $\mathrm{K} 10_{\mathrm{PCC}}$ values twice those of

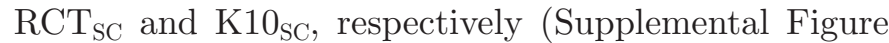
S2; https://doi.org/10.3168/jds.2019-16320). At pH 6.6 , the rennet-based curding of the milk was further developed and the $\mathrm{SD}$ values for $\mathrm{RCT}_{\mathrm{PCC}}$ higher than for $\mathrm{RCT}_{\mathrm{SC}}$, but the variability between milks remained the same on average (22\%), as it is mainly a function of the milk composition. Therefore, the curd firmness after $\mathrm{RCT}$ and the ratio $\mathrm{K} 10 / \mathrm{RCT}$ (the same for TG10) had similar values in SC and PCC conditions (Supplemental Figure S2; https://doi.org/10.3168/jds .2019-16320). These observations are consistent with previous data demonstrating that, at equal concentration of chymosin, the 2 rennet extracts we used had a similar incidence on milk coagulation when milk $\mathrm{pH}$ varied between 6.4 and 6.6 (Y. Gaüzère, unpublished results). However, we observed differences in the accuracy of K10/RCT and TG10 prediction models. Both measurements carried out using the Formoptic present on average the same repeatability $(4.9 \%)$, but depending on the characteristic of each sample of milk and how they were calculated, K10/RCT and TG10 values were probably more or less accurate.

We obtained the best MIR predictions for $\mathrm{CY}_{\mathrm{DM}}$, $\mathrm{CY}_{\mathrm{FRESH}}, \mathrm{a}_{\mathrm{SC}}$, and $\mathrm{a}_{\mathrm{PCC}}$. These traits depend primarily on the gross composition of the milk but also on the casein haplotypes (Perna et al., 2016). The diversity and frequencies of casein haplotypes in the present data set were comparable to that found by Fang et al. (2017) in a larger Montbéliarde cows population in FrancheComté. The curd firmness was highly correlated (Supplemental Table S2; https://doi.org/10.3168/jds.2019 -16320) to the protein of the milk samples $(\mathrm{r}=0.81$ and 0.82 for $\mathrm{a}_{\mathrm{SC}} \mathrm{a}_{\mathrm{PCC}}$, respectively), whereas $\mathrm{CY}$ were more correlated with the milk fat content $(\mathrm{r}=0.91$ and 0.85 for $\mathrm{CY}_{\mathrm{DM}}$ and $\mathrm{CY}_{\mathrm{FRESH}}$, respectively) because we studied whole milk samples, the usual case in the PDO cheese area of Franche-Comté. The milk samples were fresh and of good quality; correlations between SCS and CY were very weakly positive in our study, as was the observed correlation between SCS and the protein content of the samples $(\mathrm{r}=0.31$; likely indirect effect $)$. The CMP analyses differ from milk chemical ones by lower instrumental repeatability and reproducibility. We confirmed that MIR spectrometry, according to its basic principle, allowed better prediction of CMP traits closely linked to the milk composition.

\section{Performances of MIR Prediction Models Made by Different Methods}

We tested the predictive ability of models using a set of samples from 250 cows collected in 216 herds.
Thus, the calibration and validation sets included different herds reducing a possible overestimation of model robustness due to herd effect. The comparison between performance parameters of PLS and Bayesian regression models was based on the analysis of spectra cleared of the water absorption areas. Ferragina et al. (2015) compared PLS and 3 Bayesian methods (Bayes A, B, and RR) all over the spectrum, including 1,060 wavelengths, to develop prediction equations. They reported a remarkable difference in the $\mathrm{R}^{2}$ yielded by Bayes methods: 20 percentage points for RCT (reference method: Formagraph) and 8 percentage points for fresh cheese yield (reference method: micro-cheese procedure with bacterial acidification). They obtained similar performances across Bayes methods for each trait, but with an effective number of terms used far more numerous for Bayes RR and A (107-179) or Bayes B (60-72) compared with PLS $(\# \mathrm{~L}=14)$. Bayes B, a variable selection procedure, assigned small or null effects on a great number of regions, whereas Bayes RR assigned small effects to almost all the 1,060 wavelengths of the spectra, typical of shrinkage estimation procedures (as for Bayes A). In contrast, Bonfatti et al. (2017) observed that Bayesian regression models applied on whole spectra (1,060 variables) or on selected spectra regions (872 variables), gave consistent results with those observed for PLS. They concluded that Bayes $\mathrm{B}$ and $\mathrm{C}$ models performing variables exclusion were less affected by the inclusion of the noise regions than Bayes A and RR, but were not able to extract any additional information from the variable included in the water absorption regions of the spectra. When excluded, in preliminary analyses, the entire region ranging from 3,000 to $5,000 \mathrm{~cm}^{-1}$ (as we did), these authors found no effect on the performance of PLS models. After reducing noise, the prediction accuracy of Bayesian models was slightly better than PLS for coagulation traits (reference method: computerized renneting meter; CRM) and not significantly different for CY traits (reference method: rennet curd centrifugation). In the present study, retaining only 446 wavelengths, PLS and its variants gave more accurate predictions than Bayesian models whatever the CMP traits we analyzed and the differences were more pronounced for coagulation traits than for CY traits. Ferragina et al. (2017) used the Bayes $\mathrm{B}$ model to identify the combination of individual waves whose absorbance best predicted coagulation traits of ovine milk.

We applied PLS coupled with variable selection procedures (UVEPLS and RFPLS) for the prediction of CMP traits by MIR and achieved similar prediction accuracy with identical \#L using or not using variable selection before PLS. Uninformative variable elimina- 
tion is a way to eliminate those variables that clearly have no interest (Centner et al., 1996). It creates a stability criterion for each variable. If the criterion is below a specific threshold, the specific wavenumber is discarded as nonessential for the development of the prediction model. The modeling is simplified and the final dimensionality can be lower than the original. The accuracy of prediction models is expected to increase. By using selected spectra regions (i.e., spectra cleared of high noise regions), the UVEPLS procedure was tested with satisfactory results on titratable acidity, major mineral, detailed proteins, and fatty acid composition as well as on coagulation traits of bovine milk (Gottardo et al., 2015, 2016; Niero et al., 2016; Visentin et al., 2016). Visentin et al. (2016) obtained results showing a substantial increment of explained variance with UVEPLS compared with PLS only; the optimal \#L selected by PLS regression was 20 (greater than in the present study) and UVE reduced the number of wavenumbers from 873 to $110-163$ depending on the traits. The $\mathrm{R}^{2}$ in cross-validation improved from 0.46 to 0.55 for RCT, 0.46 to 0.59 for the curd-firming time, and 0.48 to 0.56 for the curd firmness $30 \mathrm{~min}$ after rennet addition. This study was carried out using a multi-breed data set of Italian cattle (Holstein-Friesian, Brown Swiss, Alpine Grey, and Simmental) and a quite different reference analysis (notably, there was no milk $\mathrm{pH}$ adjustment) which might have increased the data set variability as well as the number of optimal \#L. By retaining only 446 wavelengths, while eliminating the effect of the initial $\mathrm{pH}$ value, we reduced the number of informative variables for PLS regression.

\section{Performances of the PLS Prediction Models}

The MIR spectroscopy predictions of bovine milk coagulation properties using PLS methods have been investigated over the last decade (Dal Zotto et al., 2008; De Marchi et al., 2009, 2013; Visentin et al., 2015, 2016; Bonfatti et al., 2016), and primarily validated in crossvalidation. Prediction accuracy for the most common traits $\left(\mathrm{RCT}, \mathbf{a}_{\mathbf{3 0}}=\right.$ curd firmness $30 \mathrm{~min}$ after rennet addition, and $\mathbf{k}_{\mathbf{2 0}}=$ the time required to achieve $20 \mathrm{~mm}$ of firmness) varied greatly according to the reference analysis (instrument type and setting, pre-treatment of milk samples, and so on) spectra variable selection and mathematical pre-treatments or cattle breeds. None of these studies included measurements of milk coagulation properties with $\mathrm{pH}$ adjustment. Dal Zotto et al. (2008) developed RCT and $\mathrm{a}_{30}$ prediction equations of individual Holstein-Friesian samples using the CRM as a reference method and taking into account the influence of time of conservation and the use of preservatives. The $\mathrm{R}^{2}$ values in cross-validation ranged from 0.29 to 0.73 for RCT and 0.31 to 0.45 for $\mathrm{a}_{30}$, and were $0.64(\mathrm{RCT})$ and $0.35\left(\mathrm{a}_{30}\right)$ from samples analyzed without preservative within a day after collection. Using the same instrument (i.e., $\mathrm{CRM}$ ), investigations on other single-breed data sets showed MIR predictions of coagulation properties with similar accuracy: $\mathrm{R}^{2}$ values in cross-validation were $0.62(\mathrm{RCT})$ and 0.37 $\left(\mathrm{a}_{30}\right)$ in Italian Brown Swiss (De Marchi et al., 2009), and $0.69(\mathrm{RCT})$ and $0.32\left(\mathrm{a}_{30}\right)$ in Italian Simmental (Bonfatti et al., 2016). De Marchi et al. (2013) achieved notably better prediction models for RCT and $\mathrm{a}_{30}$ by selecting milk samples to cover a wide range of RCT and extending the testing time of analysis. Using the Formagraph instrument, they included $\mathrm{a}_{60}$, the curd firmness $60 \mathrm{~min}$ after rennet addition, to investigate the ability of MIR spectroscopy to predict noncoagulating milk using individual and bulk samples from Holstein cows. The most accurate prediction model in cross-validation was developed for $\mathrm{RCT}\left(\mathrm{R}^{2}=0.76\right)$, then $k_{20}\left(R^{2}=0.72\right)$, and highlighted the potential of MIR spectroscopy to predict this parameter and $a_{30}$ $\left(\mathrm{R}^{2}=0.70\right)$ with data with a 3 -fold variability that was detected in Bonfatti et al. (2016). By monitoring coagulation beyond the usual $31 \mathrm{~min}$, the number of noncoagulating milk samples was limited and the final curd firmness was greater for milk with longer $\mathrm{RCT}$. In that case, the lowest accuracy of prediction was obtained for $\mathrm{a}_{60}\left(\mathrm{R}^{2}=0.40\right)$. With the same reference instrument (i.e., Formagraph), lower results were obtained by Visentin et al. (2015) using a multi-breed data set of Irish cattle (Holstein-Friesian, Jersey, and Norwegian Red Cows). These authors adjusted the level of coagulant added to milk samples based on protein concentration of each individual milk samples and $\mathrm{R}^{2}$ in cross-validation (or external validation) were 0.61 (0.55), 0.59 (0.51), 0.50 (0.46), and 0.26 (0.25) for RCT, $\mathrm{k}_{20}, \mathrm{a}_{30}$, and $\mathrm{a}_{60}$, respectively. Building models using individual milk samples from multiple breeds, $\mathrm{R}^{2}$ values in cross-validation fell from 0.46 (Visentin et al., 2016) to 0.12 (Eskildsen et al., 2016) measuring RCT of full fat milk using a rheometer or RCT of skim milk using a Formagraph, respectively. As shown by Eskildsen et al. (2016), including different breeds in the calibration set most likely break the covariance structures between the protein fractions, coagulation properties, and total protein content used to calibrate PLS models. In our particular testing conditions, we reduced the variability of RCT among the individual milks from Montbéliarde cows of Franche-Comté, and thus we obtained RCT calibration equations with a low accuracy. Monitoring coagulation over at least twice the individual RCT, we performed prediction of curd firmness after RCT with 
a good accuracy in cross-validation $\left(\mathrm{R}^{2}=0.79-0.80\right)$ and with less \#L (13) than those (15-17) reported by De Marchi et al. (2013) or Visentin et al. (2015) for $\mathrm{a}_{30}$ (using a Formagraph instrument and extending the time of analysis until $60 \mathrm{~min}$ ). In this study, $\mathrm{R}^{2}$ values were lower for $\mathrm{a} 2_{\mathrm{SC}}$ than for $\mathrm{a}_{\mathrm{SC}}$ as also observed for $\mathrm{a}_{60}$ by De Marchi et al. (2013) and Visentin et al. (2015).

The PLS calibration models for CY from individual cow milk samples have been investigated over the last 5 yr, either by rennet coagulation and curd centrifugation (Colinet et al., 2013; Bonfatti et al., 2016) or by individual model cheese-making involving rennet coagulation and starter acidification (Ferragina et al., 2013, 2015). The authors obtained, just as we have, more accurate predictions of $\mathrm{CY}$ expressed in DM $\left(\mathrm{R}^{2}\right.$ in cross-validation ranging from 0.82 to 0.95 with RPD from 1.75 to 2.45) than predictions of fresh $\mathrm{CY}$ $\left(\mathrm{R}^{2}\right.$ in cross-validation ranging from 0.67 to 0.85 with RPD from 2.3 to 4.24). From a data set of 1,264 model cheeses made from individual Brown Swiss cow milk samples, Ferragina and colleagues obtained for fresh $\mathrm{CY}, \mathrm{R}^{2}$ values of 0.83 through cross-validation (Ferragina et al., 2013) and 0.66 in external validation (Ferragina et al., 2015). Our findings were better in terms of fitting statistics of both cross-validation and external validation than those of Colinet et al. (2013) who developed models from a multi-breed Walloon data set (258 Holstein, Blanc-Bleu Belge, Montbéliarde, and Brune milk samples) using a reference method close to ours but without $\mathrm{pH}$ adjustment. Compared with the present findings, Colinet et al. (2013) reported similar mean (61.9 g of curd/100 g of milk) and coefficient of variation $(\mathrm{CV}=12 \%)$ for the $\mathrm{DM}$ laboratory $\mathrm{CY}$ but a lower mean (26.8 g of curd/100 g of milk) with a higher variability $(\mathrm{CV}=30 \%)$ for the fresh laboratory CY. We could explain this last point by the data set, the lack of $\mathrm{pH}$ adjustment, or both, which might very well change the draining of the curd. Colinet et al. (2013) obtained MIR prediction models with $\mathrm{R}^{2}$ in cross-validation of 0.82 for the dry laboratory $\mathrm{CY}$ and 0.81 for the fresh laboratory $\mathrm{CY}$ with $\mathrm{RPD}$ values equal to 2.3 for both equations.

As highlighted in previous studies (Bonfatti et al., 2016; Eskildsen et al., 2016), the laboratory testing conditions, the parameters used to characterize the CMP traits, the characteristics of the milk samples from a specific breed result in specific correlations between CMP traits and milk composition (protein) or $\mathrm{pH}$. Spectra variable selection and mathematical pretreatments influence the accuracy of prediction models depending on the method used to build the equations (Bonfatti et al., 2017; Ferragina et al., 2017). This affects the predictive abilities for different CMP traits and explains the inconsistency of results across studies (Bonfatti et al., 2016).

\section{CONCLUSIONS}

The present research confirmed the ability of MIR spectroscopy to predict with excellent to fair accuracy CMP traits $\left(\mathrm{CY}_{\mathrm{DM}}, \mathrm{CY}_{\mathrm{FRESH}}, \mathrm{a}_{\mathrm{sc}}\right.$, and $\left.\mathrm{a}_{\mathrm{PCC}}\right)$ connected with milk composition traits, and for the first time, for a population of individual French Montbéliarde milks from the Franche-Comté PDO cheese production area. We developed prediction models for all the CMP traits we studied and obtained the best models with the PLS regression. Bayes methods did not outperform PLS regression in our study. We confirmed that the most important element for building MIR predictions with high quality is the reliability of the reference methods to obtain good calibration. The accuracy of the PLS model was excellent and sufficiently accurate and robust for $\mathrm{CY}_{\mathrm{DM}}$ to be applied routinely, and very good for $\mathrm{CY}_{\mathrm{FRESH}}$, suggesting good predictive ability for analytical purposes. For coagulation traits, the best results were achieved for $\mathrm{a}_{\mathrm{SC}}$ and for $\mathrm{a}_{\mathrm{PCC}}$, with fairly well accurate estimates restrained to research and development purposes (De Marchi et al., 2013; Ferrand-Calmels et al., 2014). Equations with $\mathrm{R}^{2}$ greater than 0.75 can be used in animal breeding (Soyeurt et al., 2011), but also biased estimations with low $\mathrm{R}^{2}$ in validation when several measurements are done on the same individual (Cecchinato et al., 2009). Prediction accuracy of the models we developed could be improved by increasing the number of milk samples with reference analyses. In addition, considering the requests of all actors in the dairy sector, studies are needed on 2 other production levels: herd milk and dairy milk to assess the possibility of developing CMP equations of Montbéliarde bulk milks.

\section{ACKNOWLEDGMENTS}

This study was funded by the French Ministry of Agriculture, Agro-Food and Forest (Paris, France), the French Dairy Interbranch Organization (CNIEL, Paris, France), the Regional Union of Protected Designation cheeses of Franche-Comté (URFAC, Poligny, France), and the Regional Council of Bourgogne Franche-Comté (Besançon, France), under the project FROM'MIR.

\section{REFERENCES}

Almena-Aliste, M., and B. Mietton. 2014. Cheese classification, characterization, and categorization: A global perspective. Microbiol. Spectr. 2. https://doi.org/10.1128/microbiolspec.CM-0003-2012. 
Bonfatti, V., L. Degano, A. Menegoz, and P. Carnier. 2016. Short communication: Mid-infrared spectroscopy prediction of fine milk composition and technological properties in Italian Simmental. J. Dairy Sci. 99:8216-8221. https://doi.org/10.3168/jds.2016-10953.

Bonfatti, V., F. Tiezzi, F. Miglior, and P. Carnier. 2017. Comparison of Bayesian regression models and partial least squares regression for the development of infrared prediction equations. J. Dairy Sci. 100:7306-7319. https://doi.org/10.3168/jds.2016-12203.

Breiman, L. 2001. Random forests. Mach. Learn. 45:5-32. https://doi .org/10.1023/A:1010933404324.

Cai, W., Y. Li, and X. Shao. 2008. A variable selection method based on uninformative variable elimination for multivariate calibration of near-infrared spectra. Chemom. Intell. Lab. Syst. 90:188-194. https://doi.org/10.1016/j.chemolab.2007.10.001.

Cecchinato, A., M. De Marchi, L. Gallo, G. Bittante, and P. Carnier. 2009. Mid-infrared spectroscopy predictions as indicator traits in breeding programs for enhanced coagulation properties of milk. J. Dairy Sci. 92:5304-5313. https://doi.org/10.3168/jds.2009-2246.

Centner, V., D.-L. Massart, O. E. de Noord, S. de Jong, B. M. Vandeginste, and C. Sterna. 1996. Elimination of uninformative variables for multivariate calibration. Anal. Chem. 68:3851-3858. https://doi.org/10.1021/ac960321m.

Colinet, F. G., T. Troch, O. Abbas, V. Baeten, F. Dehareng, and E. Froidmont. 2013. Potentiel d'utilisation de la spectrométrie moyen infrarouge pour prédire le rendement fromager du lait et étudier sa variabilité génétique. Renc. Rech. Ruminants 20:153-156.

Coppa, M., A. Ferlay, C. Leroux, M. Jestin, Y. Chilliard, B. Martin, and D. Andueza. 2010. Prediction of milk fatty acid composition by near infrared reflectance spectroscopy. Int. Dairy J. 20:182-189. https://doi.org/10.1016/j.idairyj.2009.11.003.

Corrieu, G., H. E. Spinnler, Y. Jomier, and D. Picque. 1988. Automated system to follow up and control the acidification activity of lactic acid starters. French Patent FR 2629612 October 1989.

Dal Zotto, R., M. De Marchi, A. Cecchinato, M. Penasa, M. Cassandro, P. Carnier, L. Gallo, and G. Bittante. 2008. Reproducibility and repeatability of measures of milk coagulation properties and predictive ability of mid-infrared reflectance spectroscopy. J. Dairy Sci. 91:4103-4112. https://doi.org/10.3168/jds.2007-0772.

de los Campos, G., J. M. Hickey, R. Pong-Wong, H. D. Daetwyler, and M. P. L. Calus. 2013a. Whole-genome regression and prediction methods applied to plant and animal breeding. Genetics 193:327345. https://doi.org/10.1534/genetics.112.143313.

de los Campos, G., P. Pérez, A. I. Vazquez, and J. Crossa. 2013b. Genome-Enabled Prediction Using the BLR (Bayesian Linear Regression) R-Package. C. Gondro, J. van der Werf, and B. Hayes, ed. Humana Press, Totowa, NJ.

De Marchi, M., C. C. Fagan, C. P. O'Donnell, A. Cecchinato, R. Dal Zotto, M. Cassandro, M. Penasa, and G. Bittante. 2009. Prediction of coagulation properties, titratable acidity, and $\mathrm{pH}$ of bovine milk using mid-infrared spectroscopy. J. Dairy Sci. 92:423-432. https://doi.org/10.3168/jds.2008-1163.

De Marchi, M., V. Toffanin, M. Cassandro, and M. Penasa. 2013. Prediction of coagulating and noncoagulating milk samples using mid-infrared spectroscopy. J. Dairy Sci. 96:4707-4715. https://doi .org/10.3168/jds.2012-6506.

Eskildsen, C. E., T. Skov, M. S. Hansen, L. B. Larsen, and N. A. Poulsen. 2016. Quantification of bovine milk protein composition and coagulation properties using infrared spectroscopy and chemometrics: A result of collinearity among reference variables. J. Dairy Sci. 99:8178-8186. https://doi.org/10.3168/jds.2015-10840.

Fang, Z. H., H. Bovenhuis, A. Delacroix-Buchet, G. Miranda, D. Boichard, M. H. P. W. Visker, and P. Martin. 2017. Genetic and nongenetic factors contributing to differences in $\alpha$ S-casein phosphorylation isoforms and other major milk proteins. J. Dairy Sci. 100:5564-5577. https://doi.org/10.3168/jds.2016-12338.

Fang, Z. H., M. H. P. W. Visker, G. Miranda, A. Delacroix-Buchet, H. Bovenhuis, and P. Martin. 2016. The relationships among bovine aS-casein phosphorylation isoforms suggest different phosphorylation pathways. J. Dairy Sci. 99:8168-8177. https://doi.org/10 $.3168 /$ jds.2016-11250.
Ferragina, A., C. Cipolat-Gotet, A. Cecchinato, and G. Bittante. 2013. The use of Fourier-transform infrared spectroscopy to predict cheese yield and nutrient recovery or whey loss traits from unprocessed bovine milk samples. J. Dairy Sci. 96:7980-7990. https:// doi.org/10.3168/jds.2013-7036.

Ferragina, A., C. Cipolat-Gotet, A. Cecchinato, M. Pazzola, M. L. Dettori, G. M. Vacca, and G. Bittante. 2017. Prediction and repeatability of milk coagulation properties and curd-firming modeling parameters of ovine milk using Fourier-transform infrared spectroscopy and Bayesian models. J. Dairy Sci. 100:3526-3538. https://doi.org/10.3168/jds.2016-12226.

Ferragina, A., G. de los Campos, A. I. Vazquez, A. Cecchinato, and G. Bittante. 2015. Bayesian regression models outperform partial least squares methods for predicting milk components and technological properties using infrared spectral data. J. Dairy Sci. 98:8133-8151. https://doi.org/10.3168/jds.2014-9143.

Ferrand-Calmels, M., I. Palhière, M. Brochard, O. Leray, J. M. Astruc, M. R. Aurel, S. Barbey, F. Bouvier, P. Brunschwig, H. Caillat, M. Douguet, F. Faucon-Lahalle, M. Gelé, G. Thomas, J. M. Trommenschlager, and H. Larroque. 2014. Prediction of fatty acid profiles in cow, ewe, and goat milk by mid-infrared spectrometry. J. Dairy Sci. 97:17-35. https://doi.org/10.3168/jds.2013-6648.

Gottardo, P., M. De Marchi, M. Cassandro, and M. Penasa. 2015. Technical note: Improving the accuracy of mid-infrared prediction models by selecting the most informative wavelengths. J. Dairy Sci. 98:4168-4173. https://doi.org/10.3168/jds.2014-8752.

Gottardo, P., M. Penasa, N. Lopez-Villalobos, and M. De Marchi. 2016. Variable selection procedures before partial least squares regression enhance the accuracy of milk fatty acid composition predicted by mid-infrared spectroscopy. J. Dairy Sci. 99:7782-7790. https://doi.org/10.3168/jds.2016-10849.

Grelet, C., J. A. Fernández Pierna, P. Dardenne, V. Baeten, and F. Dehareng. 2015. Standardization of milk mid-infrared spectra from a European dairy network. J. Dairy Sci. 98:2150-2160. https://doi .org/10.3168/jds.2014-8764.

Grubbs, F. E. 1969. Procedures for detecting outlying observations in samples. Technometrics 11:1-21. https://doi.org/10.1080/ 00401706.1969.10490657.

Hurtaud, C., H. Rulquin, M. Delaite, and R. Vérité. 1995. Appréciation de l'aptitude fromagère des laits de vaches individuels. Tests d'aptitude fromagère et rendement fromager de fabrication. Ann. Zootech. 44:385-398. https://doi.org/10.1051/animres:19950405.

Hurtaud, C., H. Rulquin, and R. Verite. 1993. Effect of infused volatile fatty acids and caseinate on milk composition and coagulation in dairy cows. J. Dairy Sci. 76:3011-3020. https://doi.org/10.3168/ jds.S0022-0302(93)77640-7.

ISO-IDF (International Organization for Standardization-International Dairy Federation). 2009. Milk-Definition and evaluation of the overall accuracy of alternative methods of milk analysis - Part 2: Calibration and quality control in the dairy laboratory. ISO 81962-IDF 128-2:2009. IDF, Brussels, Belgium.

Karoui, R., A. M. Mouazen, E. Dufour, R. Schoonheydt, and J. De Baerdemaeker. 2006. Utilisation of front-face fluorescence spectroscopy for the determination of some selected chemical parameters in soft cheeses. Lait 86:155-169. https://doi.org/10.1051/lait: 2005047.

Manuelian, C. L., G. Visentin, C. Boselli, G. Giangolini, M. Cassandro, and M. De Marchi. 2017. Short communication: Prediction of milk coagulation and acidity traits in Mediterranean buffalo milk using Fourier-transform mid-infrared spectroscopy. J. Dairy Sci. 100:7083-7087. https://doi.org/10.3168/jds.2017-12707.

Niero, G., M. Penasa, P. Gottardo, M. Cassandro, and M. De Marchi. 2016. Short communication: Selecting the most informative mid-infrared spectra wavenumbers to improve the accuracy of prediction models for detailed milk protein content. J. Dairy Sci. 99:1853-1858. https://doi.org/10.3168/jds.2015-10318.

Perez, P., and G. de los Campos. 2014. Genome-wide regression and prediction with the BGLR statistical package. Genetics 198:483495. https://doi.org/10.1534/genetics.114.164442. 
Perna, A., I. Intaglietta, E. Gambacorta, and A. Simonetti. 2016. The influence of casein haplotype on quality, coagulation, and yield traits of milk from Italian Holstein cows. J. Dairy Sci. 99:32883294. https://doi.org/10.3168/jds.2015-10463.

Sanchez, M. P., M. El Jabri, S. Minéry, V. Wolf, E. Beuvier, C. Laithier, A. Delacroix-Buchet, M. Brochard, and D. Boichard. 2018. Genetic parameters for cheese-making properties and milk composition predicted from mid-infrared spectra in a large data set of Montbéliarde cows. J. Dairy Sci. 101:10048-10061. https://doi .org/10.3168/jds.2018-14878.

Soyeurt, H., F. Dehareng, N. Gengler, S. McParland, E. Wall, D. P. Berry, M. P. Coffey, and P. Dardenne. 2011. Mid-infrared prediction of bovine milk fatty acids across multiple breeds, production systems, and countries. J. Dairy Sci. 94:1657-1667. https://doi .org/10.3168/jds.2010-3408.

Troch, T., E. Lefebure, V. Baeten, F. G. Colinet, N. Gengler, and M. Sindic. 2017. Cow milk coagulation: Process description, variation factors and evaluation methodologies. A review. Biotechnol. Agron. Soc. Environ. 21:276-287.
Viscarra Rossel, R. A., R. N. McGlynn, and A. B. McBratney. 2006 Determining the composition of mineral-organic mixes using UVvis-NIR diffuse reflectance spectroscopy. Geoderma 137:70-82. https://doi.org/10.1016/j.geoderma.2006.07.004.

Visentin, G., A. McDermott, S. McParland, D. P. P. Berry, O. A. A. Kenny, A. Brodkorb, M. A. A. Fenelon, and M. De Marchi. 2015. Prediction of bovine milk technological traits from mid-infrared spectroscopy analysis in dairy cows. J. Dairy Sci. 98:6620-6629 https://doi.org/10.3168/jds.2015-9323.

Visentin, G., M. Penasa, P. Gottardo, M. Cassandro, and M. De Marchi. 2016. Predictive ability of mid-infrared spectroscopy for major mineral composition and coagulation traits of bovine milk by using the uninformative variable selection algorithm. J. Dairy Sci. 99:8137-8145. https://doi.org/10.3168/jds.2016-11053.

Wedholm, A., L. B. Larsen, H. Lindmark-Månsson, A. H. Karlsson, and A. Andrén. 2006. Effect of protein composition on the cheesemaking properties of milk from individual dairy cows. J. Dairy Sci. 89:3296-3305. https://doi.org/10.3168/jds.S0022-0302(06)72366 -9 . 